\title{
Hypomethylation of HLA-DRB1 and its clinical significance in psoriasis
}

\author{
Wenkai Zong ${ }^{1, *}$, Yiping Ge ${ }^{1, *}$, Yue Han ${ }^{1, *}$, Xueyuan Yang ${ }^{1}, \mathbf{Q i ~ L i}^{1}$ and Min Chen ${ }^{1}$ \\ 1 Jiangsu Key Laboratory of Molecular Biology for Skin Diseases and STIs, Institute of Dermatology, Chinese Academy of \\ Medical Sciences and Peking Union Medical College, Nanjing, China \\ * These authors have contributed equally to this work \\ Correspondence to: Min Chen, email: drchenmin@126.com
}

Keywords: psoriasis, HLA-DRB1, gene methylation, mRNA

Received: July 20,2016 Accepted: September 29, $2016 \quad$ Published: October 04, 2016

\section{ABSTRACT}

Increasing evidences indicate that the abnormal DNA methylation is involved in the pathogenesis of psoriasis. A number of SNPs in HLA-DRB1 have been found being associated with the risk of psoriasis, however it is unclear that metylation status within HLA-DRB1 in psoriasis. Here, DNA and RNA were obtained from epidermis of 56 patients with plaque psoriasis and 28 healthy volunteers served as the control group. For the first time, we discovered mean methylation rate for HLA-DRB1 is $52.2 \%, 64.3 \%$ and $68.1 \%$ in epidermis from psoriatic lesions, psoriatic non-lesions and healthy controls, respectively. HLA-DRB1 methylation in psoriatic lesions is significantly lower than in psoriatic non-lesions $(t=13.077, p<0.001)$. However, there is no significant difference for HLA-DRB1 methylation between in psoriatic non-lesions and in healthy controls $(t=1.046, p=0.299)$. HLA-DRB1 methylation in psoriatic lesions is negatively correlated to PASI score $(r=-0.431, p=0.001)$. HLA-DRB1 methylation in psoriatic lesions of the patients with onset age $\leq 18$ years is significantly lower than the other patients $(t=3.968, p<0.001)$. Meanwhile, HLADRB1 mRNA expression is significantly increased in psoriatic lesions comparing to psoriatic non-lesions $(t=12.119, p<0.001)$. There are no significant difference for HLA-DRB1 mRNA expression between in psoriatic non-lesions and in healthy controls $(t=1.172, p=0,245)$. Moreover, HLA-DRB1 mRNA expression is negatively associated with HLA-DRB1 methylation in psoriatic lesions $(r=0.932, p<0.001)$. In conclusions, our results showed hypomethylation of HLA-DRB1 is associated with HLA-DRB1 mRNA expression and severity of the disease, indicating that hypomethylation of HLA-DRB1 may play roles in the pathogenesis of psoriasis.

\section{INTRODUCTION}

Psoriasis is a common chronic skin disorder that affected about $1 \%-3 \%$ of the world population, and the pathogenesis of psoriasis is still unclear. Based on current findings, psoriasis is generally considered as an autoimmune disease caused by $\mathrm{T}$ cell-mediated hyperproliferation of the keratinocytes [1]. Increasing evidences indicate that psoriasis is also a genetic disease triggered by multiple environmental factors, such as smoking, chronic infections, stress, climate changes. Many studies about the association between human leukocyte antigens (HLA) and psoriasis have been reported for a long time $[2,3]$. In recent studies, much attention have been paid on the role of epigenetic changes (e.g. DNA methylation) in psoriasis, and the abnormal epigenetic modification of several molecules has been observed in the psoriatic lesions of patients [4, 5]; however, researchers still need to make greater efforts to illustrate the mechanism of how the aberrant epigenetic modifications would affect the pathogenesis of psoriasis.

Human leukocyte antigen class (HLA)-DRB1 is a transmembrane heterodimer cell surface receptor with $\alpha$ and $\beta$ chains, and each contains extracellular domains, membrane-spanning domain and a tail anchored in the cytoplasm. The $\alpha$ chain of HLA-DRB1 lack polymorphism, and the $\beta$ chain is encoded by 4 loci DRB1, DRB3, DRB4 and DRB5 [6]. HLA-DRB1 is a 
major histocompatibility complex (MHC) class II protein that expressed constitutively by antigen-presenting cells (APCs), such as dendritic cells, macrophages etc. The expression of HLA-DRB1 is important for APCs, because HLA-DRB1 can determine the efficiency of APCs to present antigen to T cells [7].

Several studies have examined the relationship between HLA-DRB1 and cancer, including parotid cancer [8] and ovarian cancer [9]. Previous studies suggested that immunohistochemically detectable HLA-DRB1 expression is associated with better prognosis in patients with colorectal cancer $[10,11,12]$. The relationship between HLA-DRB1 and AIDs has also been reported. The level of expression of HLA-DRB1 alleles have been associated with the development of systemic lupus erythematosus (SLE), rheumatoid arthritis (RA), systemic sclerosis (SSc) and multiple sclerosis (MS) [13].

Although the HLA class II locus is the strong genetic risk factor for RA, the relationship between HLA class II alleles and lymphocyte activation remains unclear. The presence of HLA-DR was not confined to activated CD4+ and CD8+ T cells [14]. Nagafuchi et al. [15] studied immunophenotyping of peripheral blood mononuclear cells on RA patients with HLA-DRB1genotype and found the frequency of memory CXCR4+CD4+ T cells was significantly related to severity of disease. A significantly higher frequency of memory CXCR4+CD4+ T cells was found in the patients with one or more susceptible HLA-DR haplotypes, moreover, on B cells, the frequency of memory CXCR4+CD4+ T cells significantly was associated with the HLA-DR expression, which suggested that the interaction between HLA-DR and T cell receptors can regulate the memory $\mathrm{CXCR} 4+\mathrm{CD} 4+\mathrm{T}$ cells.

In psoriasis, the role of HLA-DRB1 has also been well investigated. As early as 1982, VB Morhenn et al first observed the abnormal expression of HLA-DRB1 in skin samples of patients with psoriasis [16]. Since then, the polymorphism of HLA-DRB1 and its relationship with the psoriasis, as well as the role of HLA-DRB1 alleles in the pathogensis of psoriasis have been reported in different works $[17,18,19,20]$. The functional role of the HLA-DRB1 molecule in psoriasis remains enigmatic. In psoriasis, Keratin 17 is a major target antigen of autoreactive $\mathrm{T}$ cells. On Keratin 17, the epitopes S1 (118-132), S2 (169-183), S4 (323-337) and S4 (348362) of HLA-DRB $1 * 04, * 07$-restricted T cell epitope regions are immunodominant HLA-DRB1-restricted T cell epitopes [21]. Magalhães et al [22] demonstrate these polymorphisms of HLA class I and II may be genetic risk for severity of the disease in a case-control study of patients with mild or severe psoriasis, and found that alleles HLA-DRB1*07, $\mathrm{B} * 37, \mathrm{Cw} * 06$ and $\mathrm{Cw}^{*} 12$ were correlated with severe disease course.

However, to our knowledge, the methylation status of HLA-DRB1 in psoratic patients has not yet been investigated. In our previous work, we already proved that hypermethylation of HLA-C may play an important role in psoriasis [23]. In this study, we will focus on the methylation status of HLA-DRB1 in psoriasis and its relationship with the disease.

\section{RESULTS}

\section{HLA-DRB1 hypomethylation}

First, we performed bisulfite sequencing PCR (BSP) analysis to determine the methylation status in the promoter regions of HLA-DRB1 in epidermis of psoriatic lesions, psoriatic non-lesions and healthy volunteers. Methylation of HLA-DRB1 was found in all samples, and bisulfite sequencing results indicated that 3-18 of 18 $\mathrm{CpG}$ dinucleotides in the promoter region of the HLADRB1 were methylated (Figure 1 and 2). In psoriatic lesions, psoriatic non-lesions and healthy controls, the mean rate of promoter methylation for HLA-DRB1 was $52.26 \pm 2.66 \%, 64.34 \pm 2.30 \%$ and $68.11 \pm 2.18 \%$, respectively. The frequency of promoter methylation for HLA-DRB1 in psoriatic lesions was significantly lower than in psoriatic non-lesions $(t=13.077, p<0.001)$, and there is no significant difference for the rate of HLADRB1 methylation between in psoriatic non-lesions and healthy controls $(t=1.046, p=0.299)$ (Figure 3$)$. The mean methylation rate of HLA-DRB1 of the minors group with onset age $\leq 18$ years is significantly lower than the adults group with onset age $>18$ years in psoriatic lesions $(37.43 \pm 5.10 \%$ and $58.19 \pm 2.61 \% ; t=3.968, p<0.001)$ (Figure 4). The mean methylation rate of HLA-DRB1 in psoriatic lesions is negatively correlated to PASI score $(r$ $=-0.431, p=0.001)$ (Figure 5).

\section{HLA-DRB1 mRNA expression}

In order to examine whether HLA-DRB1 methylation can affect the level of HLA-DRB1 expression in psoriasis, we performed RT-PCR analysis to determine the level of HLA-DRB1 mRNA in the specimens of epidermis. We have observed the expression of HLADRB1 in $94.6 \%(53 / 56)$ psoriatic lesions, $92.9 \%(52 / 58)$ psoriatic non-lesions and $92.9 \%(26 / 28)$ epidermis of healthy controls. The mean mRNA expression of HLADRB1 in psoriatic lesions, psoriatic non-lesions and healthy controls is $0.57 \pm 0.03,0.47 \pm 0.03$ and $0.41 \pm 0.03$, respectively (Figure 6). HLA-DRB1 mRNA expression in psoriatic lesions was higher than psoriatic non-lesions $(t=$ $12.119, p<0.001$ ). There are no significant difference for the expression of HLA-DRB1 mRNA between in psoriatic non-lesions and healthy controls $(t=1.172, p=0.245)$. The mean value of HLA-DRB1 mRNA expression is negatively correlated to the methylation of HLA-DRB1 in psoriatic lesions $(r=-0.932, p<0.001)$ (Figure 7). 


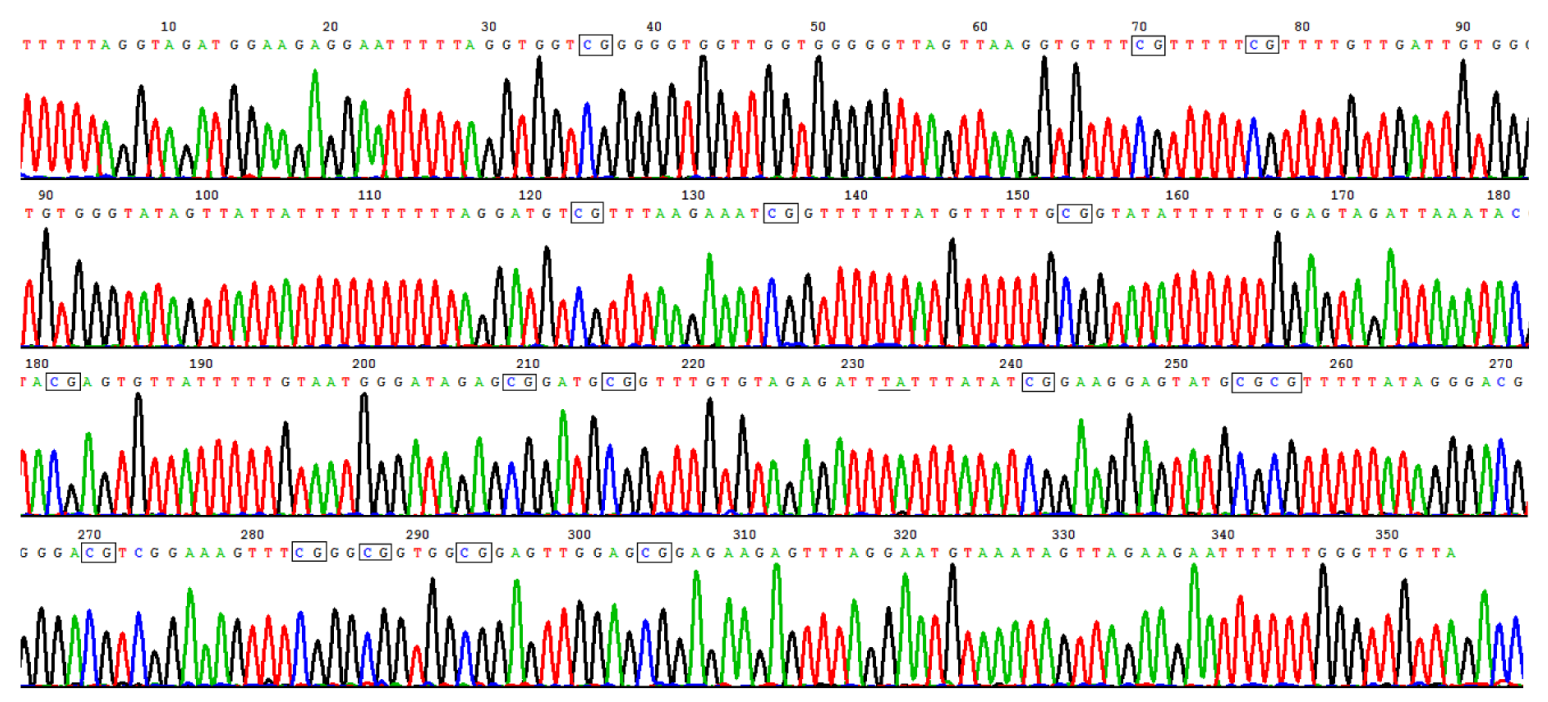

Figure 1: High methylation rate in HLA-DRB1 promoter in epidermis of healthy controls. Representative product of sodium bisulfite genomic sequencing showed HLA-DRB1 methylation occurred in 17 out of $18 \mathrm{CpG}$ sites in healthy controls. The rectangles show methylated $\mathrm{CpG}$, and the underline show unmethylated $\mathrm{CpG}$ where $\mathrm{C}$ change to $\mathrm{T}$ after bisulphate treatment.

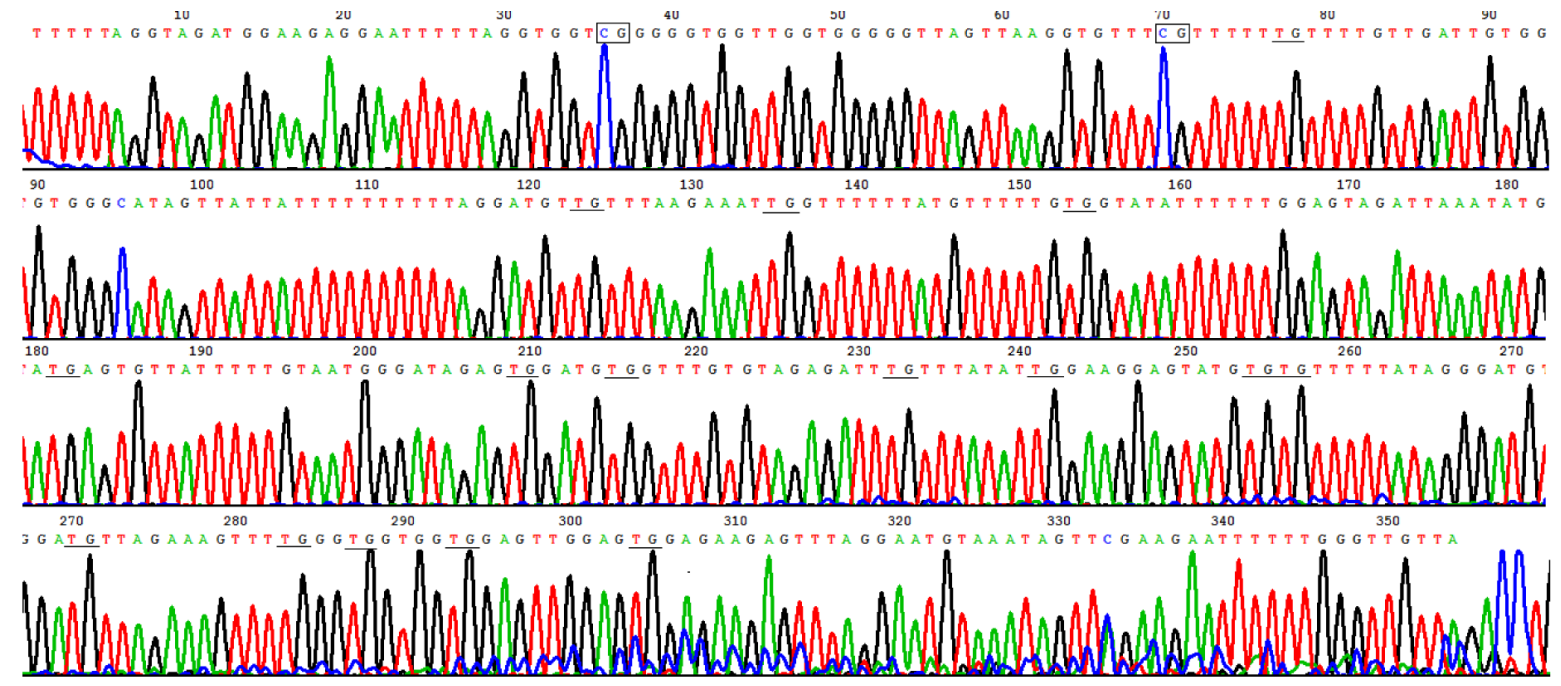

Figure 2: Hypomethylation in HLA-DRB1 promoter in psoriatic lesional epidermis. Example of sodium bisulfite genomic sequencing product in psoriatic lesion showed HLA-DRB1 methylation only occurred in 2 out of $18 \mathrm{CpG}$ sites. The rectangles show methylated $\mathrm{CpG}$, and the underline show unmethylated $\mathrm{CpG}$ where $\mathrm{C}$ change to $\mathrm{T}$ after bisulphate treatment.

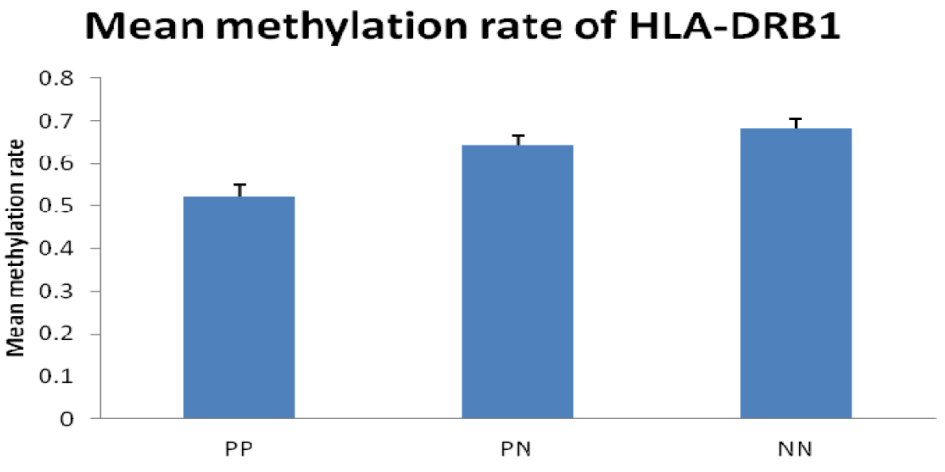

Figure 3: Mean methylation rate of HLA-DRB1 in psoriatic skin $(n=56)$ and healthy controls $(n=28)$. The frequency of promoter methylation for HLA-DRB1 in PP was significantly lower than in $\mathrm{PN}(t=13.077, p<0.001)$, and there is no significant difference between the rate of promoter methylation in PN and NN. PP: psoriatic lesion, PN: psoriatic non-lesion, NN: healthy controls 


\section{HLA-DRB1 methylation of different age groups in psoriatic lesions}

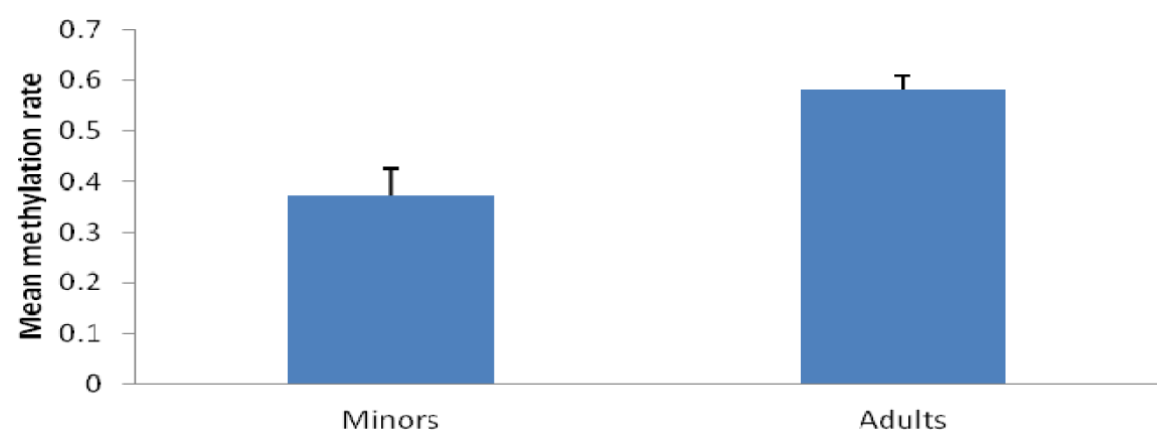

Figure 4: HLA-DRB1 methylation of different age groups in psoriatic lesions. Mean methylation rate of HLA-DRB1 of the minors group with onset age $\leq 18$ years is significantly lower than the adults group with onset age $>18$ years in psoriatic lesions $(37.4 \pm 20.4 \%$ and $58.2 \pm 16.5 \% ; t=3.968, p<0.001)$.

\section{Mean methylation of $H L A-D R B 1$ in psoriatic lesions is correlated to PASI}

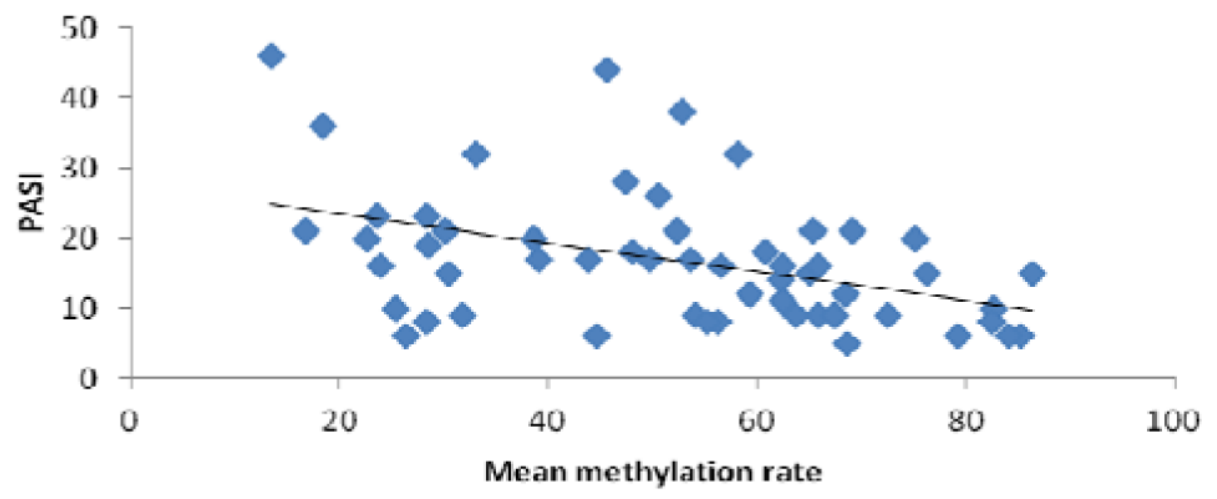

Figure 5: The mean methylation rate of HLA-DRB1 in psoriatic lesions is negatively correlated to PASI score $(r=$ $-0.431, p=0.001)$.

\section{The mean value of HLA-DRB1 mRNA expression}

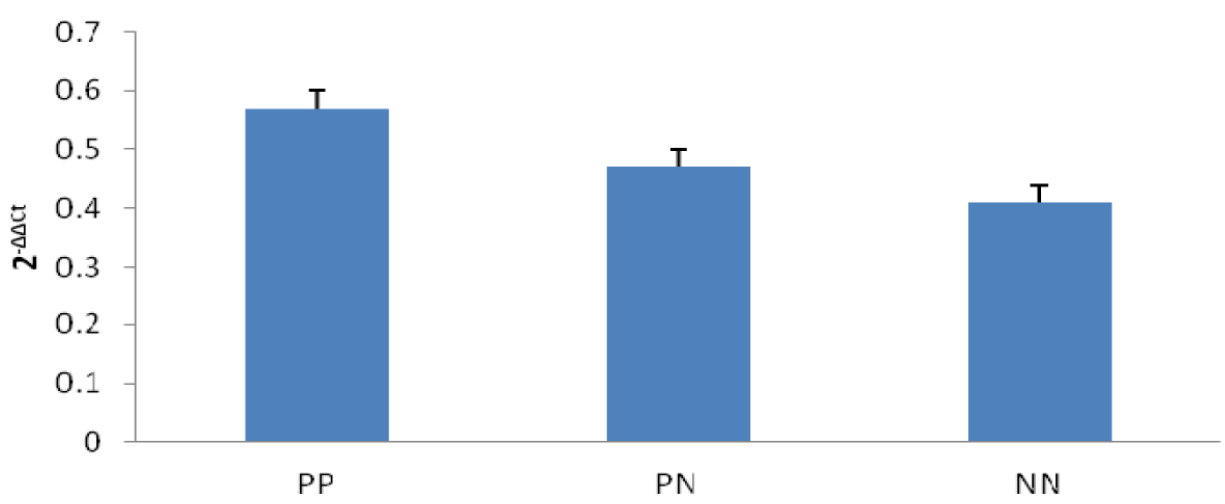

Figure 6: Realtime RT-PCR to detect for HLA-DRB1 mRNA expression. The mean value of HLA-DRB1 mRNA expression $(2-\Delta \Delta \mathrm{Ct})$ was significantly higher in PP than PN, while there is no significant difference between PN and NN. PP: psoriatic lesion, PN: psoriatic non-lesion, NN: healthy controls 


\section{DISCUSSION}

DNA methylation is an important epigenetic mechanism that can affect gene expression without changing the DNA sequence. Some recent studies indicated that aberrant methylation status of HLA genes may be involved in the pathogenesis of some diseases. The abnormal methylation of HLA-G gene has been found in cancers $[24,25]$ and preeclampsia [26]; and hypermethylation of HLA-A, B, C was observed in esophageal squamous cell carcinoma (ESCC) [27]. For HLA-DRB1, Hu et al. proved that HLA-DRB1B1 methylation changes can promote the occurrence and progression of ESCC [28]; Yu et al. reported the association between brain DNA methylation of HLADRB1B5 and pathological diagnosis of Alzheimer disease [29]; Graves et al. discovered that methylation at the HLA-DRB1B1 locus in CD4+ T cells are associated with multiple sclerosis [30].

In our study, we first reported the hypomethylation of HLA-DRB1 in psoriatic epidermis; more importantly, our data proved that methylation of HLA-DRB1 is negatively correlated with the severity of the disease, suggesting that the methylation status of HLA-DRB1 can become a potential bio-marker for the diagnosis or evaluating the efficacy of treatment of psoriasis. Interestingly, previous work has also correlated aberrant methylation of HLA-DRB1 with the prognosis of some diseases, thus, we hypothesis that methylation status of HLA-DRB1 may also affect the prognosis and recurrence of psoriasis, which can be proposed as our future direction for the investigation of HLA-DRB1 methylation in psoriasis.

Roberson et al. [31] found that the frequency of methylation was strongly associated with gene expression at a nearby locus at only $12 / 1,100 \mathrm{CpG}$ sites, suggesting that the level of methylation may only affect the expression of a small size of genes. The promoter and 3'-UTR of HLA-DRB1 can antagonistically regulate the gene expression [32]. In order to explore if HLADRB1 promoter hypomethylation can directly affect the expression of HLA-DRB1, we also examined HLADRB1 mRNA expression in all epidermis from psoriatic lesions, psoriatic non-lesions and healthy controls. The expression of HLA-DRB1 mRNA was significantly increased in psoriatic epidermis when compared with the healthy volunteers, and the mean value of HLA-DRB1 mRNA expression is negatively correlated to the promoter methylation of HLA-DRB1. Our results indicated that hypomethylation of HLA-DRB1 may be one of the leading causes that induced the overexpression of HLA-DRB1 in psoriatic epidermis, which may promote the development of the disease.

The impact of the hypomethylation and overexpression of HLA-DRB1 on keratinocytes is still unclear. It was demonstrated that several peptides on keratin 17 can serve as immunodominant T-cell epitopes and stimulate peripheral blood lymphocytes of HLA DRB $1 * 04$ and/or $* 07$ positive patients with psoriasis. Moreover, the peptide ligands are able to inhibit proliferation of $\mathrm{T}$ cells and keratinocyte in psoriasis [33].

One limitation of present study is that we only performed analysis of HLA-DRB1 expression on mRNA level for the limited epidermal specimens, and the expression of HLA-DRB1 protein in samples have not been examined. For every patient, only a small piece of epidermis could be collected, thus the samples were not enough for both nucleic acid level and

\section{Methylation of HLA-DRB1 is correlated to the mRNA expression}

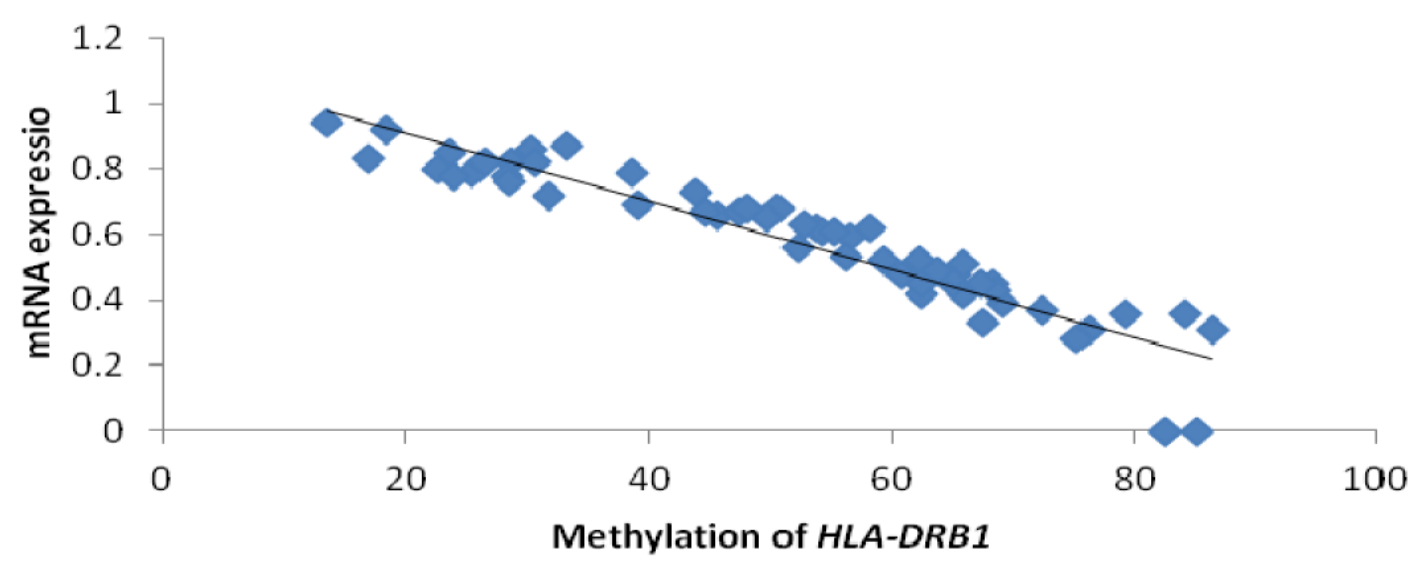

Figure 7: The promoter methylation of HLA-DRB1 is negatively correlated to the mean value of HLA-DRB1 mRNA expression in psoriatic lesions $(r=-0.932, p<0.001)$. 
Table1: Demographics and disease parameters of patients with psoriasis

\begin{tabular}{|c|c|c|c|c|c|c|c|c|c|c|}
\hline Case & Gender & $\begin{array}{l}\text { Age } \\
(y)\end{array}$ & $\begin{array}{l}\text { Length } \\
\text { of disease (y) }\end{array}$ & $\begin{array}{l}\text { Onset } \\
\operatorname{age}(y)\end{array}$ & PASI & $\begin{array}{l}\text { Family } \\
\text { history }\end{array}$ & $\begin{array}{l}\text { Methy } \\
\text { in } \\
\text { lesions \% }\end{array}$ & $\begin{array}{l}\text { Methy } \\
\text { in non- } \\
\text { lesions } \%\end{array}$ & $\begin{array}{l}\text { Expression } \\
\text { in lesions }\end{array}$ & $\begin{array}{l}\text { Expression } \\
\text { in non- } \\
\text { lesions }\end{array}$ \\
\hline 1 & $\mathrm{M}$ & 32 & 1 & 31 & 21 & - & 52.3 & 71.2 & 0.56 & 0.43 \\
\hline 2 & $\mathrm{M}$ & 46 & 20 & 26 & 32 & - & 58.2 & 74.5 & 0.62 & 0.51 \\
\hline 3 & $\mathrm{M}$ & 45 & 10 & 35 & 16 & - & 56.5 & 67.8 & 0.59 & 0.48 \\
\hline 4 & $\mathrm{M}$ & 28 & 8 & 20 & 9 & - & 65.9 & 83.3 & 0.42 & 0.35 \\
\hline 5 & $\mathrm{M}$ & 65 & 8 & 57 & 44 & - & 45.6 & 57.6 & 0.66 & 0.49 \\
\hline 6 & $\mathrm{M}$ & 30 & 6 & 24 & 12 & - & 68.4 & 88.5 & 0.45 & 0.37 \\
\hline 7 & $\mathrm{~F}$ & 30 & 14 & 16 & 19 & + & 28.5 & 54.3 & 0.82 & 0.73 \\
\hline 8 & $\mathrm{M}$ & 48 & 1 & 47 & 21 & - & 69.2 & 76.6 & 0.39 & 0.32 \\
\hline 9 & $\mathrm{~F}$ & 52 & 3 & 49 & 15 & - & 65.1 & 82.4 & 0.45 & 0.38 \\
\hline 10 & $\mathrm{M}$ & 21 & 3 & 18 & 11 & - & 62.5 & 59.1 & 0.42 & 0.34 \\
\hline 11 & $\mathrm{~F}$ & 46 & 3 & 43 & 15 & - & 86.4 & 86.2 & 0.31 & 0.23 \\
\hline 12 & $\mathrm{M}$ & 36 & 10 & 26 & 9 & + & 31.7 & 48.7 & 0.72 & 0.58 \\
\hline 13 & $\mathrm{~F}$ & 33 & 20 & 13 & 21 & + & 16.8 & 39.1 & 0.83 & 0.69 \\
\hline 14 & $M$ & 18 & 1 & 17 & 6 & + & 44.6 & 48.5 & 0.67 & 0.53 \\
\hline 15 & $\mathrm{~F}$ & 38 & 20 & 18 & 17 & - & 53.7 & 62.2 & 0.62 & 0.49 \\
\hline 16 & $\mathrm{~F}$ & 19 & 2 & 17 & 10 & + & 25.4 & 42.5 & 0.79 & 0.65 \\
\hline 17 & $\mathrm{M}$ & 48 & 10 & 38 & 9 & - & 54.2 & 65.6 & 0.61 & 0.65 \\
\hline 18 & $\mathrm{~F}$ & 52 & 20 & 32 & 21 & - & 65.3 & 75.1 & 0.48 & 0.32 \\
\hline 19 & $M$ & 43 & 1 & 42 & 10 & - & 82.6 & 86.4 & 0 & 0 \\
\hline 20 & $M$ & 35 & 6 & 29 & 23 & - & 28.3 & 48.2 & 0.78 & 0.72 \\
\hline 21 & $M$ & 20 & 5 & 15 & 36 & + & 18.4 & 42.6 & 0.92 & 0.78 \\
\hline 22 & $\mathrm{~F}$ & 29 & 1 & 28 & 9 & - & 67.5 & 79.4 & 0.33 & 0.25 \\
\hline 23 & $\mathrm{M}$ & 22 & 4 & 18 & 23 & + & 23.6 & 48.5 & 0.85 & 0.78 \\
\hline 24 & $\mathrm{M}$ & 32 & 8 & 24 & 6 & - & 79.2 & 84.1 & 0.36 & 0.27 \\
\hline 25 & $\mathrm{M}$ & 36 & 5 & 29 & 26 & - & 50.6 & 72.3 & 0.68 & 0.64 \\
\hline 26 & $\mathrm{M}$ & 58 & 16 & 42 & 28 & - & 47.5 & 72.1 & 0.67 & 0.61 \\
\hline 27 & $\mathrm{M}$ & 64 & 1 & 63 & 20 & - & 38.6 & 49.2 & 0.79 & 0.72 \\
\hline 28 & $\mathrm{~F}$ & 34 & 16 & 18 & 8 & - & 56.2 & 55.4 & 0.53 & 0.37 \\
\hline 29 & $\mathrm{M}$ & 17 & 5 & 12 & 46 & + & 13.5 & 32.6 & 0.94 & 0.86 \\
\hline 30 & $\mathrm{M}$ & 49 & 15 & 34 & 38 & - & 52.8 & 67.7 & 0.63 & 0.58 \\
\hline 31 & $\mathrm{~F}$ & 22 & 3 & 19 & 6 & + & 26.4 & 36.8 & 0.82 & 0.65 \\
\hline 32 & $\mathrm{~F}$ & 55 & 33 & 22 & 21 & + & 30.2 & 41.6 & 0.86 & 0.73 \\
\hline 33 & $\mathrm{~F}$ & 28 & 1 & 27 & 17 & - & 49.7 & 59.3 & 0.65 & 0.57 \\
\hline 34 & $\mathrm{~F}$ & 40 & 3 & 37 & 17 & - & 39.1 & 42.9 & 0.69 & 0.61 \\
\hline 35 & $M$ & 39 & 30 & 9 & 8 & + & 28.4 & 39.2 & 0.76 & 0.65 \\
\hline 36 & $\mathrm{M}$ & 22 & 5 & 17 & 20 & + & 22.6 & 38.6 & 0.80 & 0.72 \\
\hline 37 & $\mathrm{M}$ & 43 & 1 & 42 & 6 & - & 85.2 & 86.5 & 0 & 0 \\
\hline 38 & $\mathrm{~F}$ & 23 & 10 & 13 & 9 & - & 72.5 & 84.8 & 0.37 & 0 \\
\hline 39 & $\mathrm{M}$ & 52 & 17 & 35 & 15 & - & 76.3 & 86.6 & 0.31 & 0.22 \\
\hline 40 & $\mathrm{M}$ & 39 & 1 & 38 & 5 & - & 68.6 & 78.2 & 0.43 & 0.25 \\
\hline 41 & $\mathrm{~F}$ & 18 & 1 & 17 & 16 & + & 23.9 & 38.6 & 0.78 & 0.65 \\
\hline 42 & $\mathrm{M}$ & 46 & 2 & 44 & 14 & - & 62.3 & 72.7 & 0.52 & 0.43 \\
\hline 43 & $\mathrm{~F}$ & 21 & 1 & 20 & 8 & - & 82.5 & 85.3 & 0 & 0 \\
\hline 44 & $\mathrm{~F}$ & 23 & 7 & 16 & 20 & - & 75.2 & 88.4 & 0.28 & 0.26 \\
\hline 45 & $\mathrm{M}$ & 44 & 11 & 33 & 17 & - & 43.8 & 47.5 & 0.73 & 0.62 \\
\hline 46 & $\mathrm{M}$ & 48 & 5 & 43 & 18 & - & 48.1 & 60.8 & 0.68 & 0.59 \\
\hline 47 & $\mathrm{M}$ & 52 & 3 & 49 & 8 & - & 55.2 & 75.6 & 0.61 & 0.42 \\
\hline 48 & $\mathrm{~F}$ & 46 & 2 & 44 & 9 & - & 67.4 & 81.2 & 0.45 & 0.28 \\
\hline 49 & $\mathrm{M}$ & 29 & 5 & 24 & 12 & - & 59.3 & 61.3 & 0.52 & 0.37 \\
\hline
\end{tabular}




\begin{tabular}{|c|c|c|c|c|c|c|c|c|c|c|}
\hline 50 & $\mathrm{M}$ & 53 & 5 & 48 & 18 & - & 60.8 & 70.6 & 0.48 & 0.32 \\
\hline 51 & $\mathrm{M}$ & 32 & 1 & 31 & 16 & - & 62.5 & 74.8 & 0.45 & 0.35 \\
\hline 52 & $\mathrm{M}$ & 33 & 8 & 25 & 16 & - & 65.9 & 76.2 & 0.51 & 0.39 \\
\hline 53 & $\mathrm{~F}$ & 26 & 8 & 18 & 32 & + & 33.1 & 45.5 & 0.87 & 0.85 \\
\hline 54 & $\mathrm{~F}$ & 32 & 2 & 30 & 9 & - & 63.7 & 75.1 & 0.49 & 0.26 \\
\hline 55 & $\mathrm{M}$ & 43 & 6 & 37 & 15 & + & 30.5 & 44.5 & 0.82 & 0.76 \\
\hline 56 & $\mathrm{~F}$ & 51 & 1 & 50 & 6 & - & 84.2 & 88.5 & 0.36 & 0.18 \\
\hline Mean & & 37.25 & 7.41 & 29.8 & 16.77 & & 52.3 & 64.3 & 0.59 & 0.49 \\
\hline
\end{tabular}

protein level analysis. To investigate the specific role of hypomethylation of HLA-DRB1 in the pathogenesis of psoriasis, in the following step, we plan to perform animal studies using the existing psoratic models.

To the best of our knowledge, this is the first paper reporting an association between methylation of HLA-DRB1 gene and psoriasis. Overall, abnormal hypomethylation of HLA-DRB1 gene promoter has been observed in psoriatic epidermis. Hypomethylation of HLA-DRB1 associated with the mRNA level of HLADRB1 expression and severity of the disease, indicating that hypomethylation of HLA-DRB1 may also play a potential role in the pathogenesis of psoriasis.

\section{MATERIALS AND METHODS}

\section{Subjects and skin samples}

Skin samples were collected from 56 patients with active plaque psoriasis ( 21 females and 35 males) and 28 healthy volunteers. Their characteristics are summarized in Table 1. A paired psoriatic lesion (PP) and psoriatic non-lesion (PN) were derived from the same patient, thus a total number of 56 paired PP/PN samples were obtained. The psoriatic non-lesion specimens were taken from the sites more than $5 \mathrm{~cm}$ far away lesion edge. The patients were between 18 to 65 years old (mean $37.25 \pm 1.68$ ), with the length of disease ranged from 1 to 33 years (mean $7.41 \pm 0.99$ ). Among all 56 patients, the onset age of 40 cases was more than 18 years old. The severity of the disease was evaluated using the psoriasis area severity index (PASI) scoring system and the score was ranged from 4 to 46 (mean 16.78 \pm 1.27 ). Patients that received either systemic or topical therapy 6 weeks prior to this study and pregnant patients were excluded. Healthy volunteers $(\mathrm{NN})$ were people who did not have skin lesions and without self-reported psoriasis history. The $\mathrm{NN}$ group and $\mathrm{PP} / \mathrm{PN}$ group has a qualified match in age and sex. All tissue specimens were obtained following the ethical guidelines mandated by the ethical committee of Institute of Dermatology, Chinese Academy of Medical Sciences who approved this study. All candidates were approached using approved ethical guidelines and those who agreed to participate in this study were required to sign the consent forms. Tissue specimens on trunk or limbs were obtained using a 6-mm punch biopsy under aseptic conditions with local anesthesia. The specimens were frozen in liquid nitrogen and stored at $-80{ }^{\circ} \mathrm{C}$ until processed.

\section{Epidermal isolation, DNA and RNA extraction}

Epidermis were separated from skin specimens using $0.25 \%$ Dispase (Roche, USA) for 6-12 hours; next, the samples were placed on ice, and homogenized in sterilized 5-mL tissue grinders; then, DNA and total RNA were extracted from the epidermis samples using QIAamp DNA Mini kit and RNA Mini kit (Qiagen, Valentia, CA) following the manufacturer's protocols. The quality of the extracted total RNA were assessed using electrophoresis on $1 \%$ agarose gels, by visualizing the $18 \mathrm{~S}$ and $28 \mathrm{~S}$ RNA bands under UV light.

\section{Bisulphite conversion}

Bisulphite conversion of genomic DNA was performed was performed using EpiTectH Bisulfite kit (Qiagen) following the manufacturer's instructions. Briefly, genomic DNA samples (50 150 ng DNA/sample) were denatured using $\mathrm{NaOH}$, and then treated with sodium bisulfite; next, the samples were desulfonated,and purified using silica-membrane columns; finally, the treated DNAs were suspended in $10 \mu \mathrm{TE}$ buffer either for immediate measurement, or stored at $-20{ }^{\circ} \mathrm{C}$ for future analysis.

\section{Sodium bisulfite genomic sequencing PCR}

To investigate the methylation status of the HLA-DRB1 promoter, we mapped the corresponding $\mathrm{CpG}$ island in HLA-DRB1 by CpGplot (EBI Tools, EMBOSS CpGPlot; http://www.ebi.ac.uk/ emboss/cpgplot). CpG-enriched region of HLADRB1 was amplified using primers as follow: F-5'TTTTAGGTAGATGGAAGAGGAA $-3^{\prime}$ and R-5'AACAACCCAAAAAATTCTTCTA -3 ' (352bp). Modified DNAs were used for PCR analysis, and the 
products include $18 \mathrm{CpG}$ sites and span part of the promoter of HLA-DRB1. The reaction was set up at a total volume of $25 \mathrm{ml}$ containing $1 \mathrm{ml}$ sample DNA, 0.2 mM dNTPs, $0.5 \mathrm{mM}$ primers, $2.5 \mathrm{mM} \mathrm{MgCl} 2$, 16buffer II, and 1.25 unit HotTaq DNA polymerase (Takara, JP).The thermocycle profiles was $94{ }^{\circ} \mathrm{C}$ for 9 minutes to activate the polymerase; 44 cycles at $94{ }^{\circ} \mathrm{C}$ for 30 seconds, $55^{\circ} \mathrm{C}$ for 30 seconds, and $68{ }^{\circ} \mathrm{C}$ for 45 seconds; and a 7-minute terminal extension at $68^{\circ} \mathrm{C}$. The amplified DNA fragments were then cloned into plasmids using a TOPO TA Cloning kit (Invitrogen, Carlsbad, CA) according to manufacturer's instructions. The clones were then screened by colony PCR, and purified using the Qiaquick kit (Qiagen, CA). Next, individual clones were sequenced on an ABI PRISM 3730 automated sequencer, and the sequence electropherograms were aligned using Sequence Navigator software (Applied Biosystems). Quantitative methylation rates were estimated from sequence traces using the ESME software.

\section{Real-time RT-PCR analysis for mRNA expression}

Total RNA extracted from epidermis was converted to amplified cDNA using a GoScript ${ }^{\mathrm{TM}}$ Reverse Tanscription System Kit (Promega, USA) on the DNA Engine Opticon System (ABI GeneAmp PCR System 7300, USA), and cDNAs were aliquoted and stored at -20 ${ }^{\circ} \mathrm{C}$. In brief, the cDNA synthesis contained $5 \mathrm{uL}$ of $10 \times$ Taqman RT buffer; $11 \mathrm{uL}$ of $25 \mathrm{mM} \mathrm{MgCl} 2 ; 10 \mathrm{uL}$ of deoxy NTPs; 2.5 uL of Oligo d(T)16 primer; $1 \mathrm{uL}$ of RNase inhibitor; $1.25 \mathrm{uL}$ of Multiscribe reverse transcriptase, and $1 \mathrm{ug}$ of RNA. Two separate $50 \mathrm{uL}$ reactions for each RNA were performed and combined together. Each cDNA batch reaction had a maximum of 24 tubes to ensure the best sample quality. Primers were as follow: HLA-DRB1 F- 5' - TGCCAAGTGGAGCACCCAA -3' and R-5' - GCATCTTGCTCTGTGCAGAT -3'; $\beta$-ACTIN F-5' - CAGTCGGTTGGAGCGAGCAT -3' and R-5'GGACTTCCTGTAACAACGCATCT -3'. The primer test results showed that all cDNA amplified with a single band. This detection ensured that the primers were specific to HLA-DRB1. Quantitative PCR (qPCR) was performed on an ABI 7900HT Sequence Detection System (Applied Biosystems) in 384-well plates. The samples were run in triplicate using one plate per gene. The reaction was performed in a $12.5 \mathrm{uL}$ total volume with $6.5 \mathrm{uL}$ of $2 \times$ SYBR Green Master Mix (Applied Biosystems); 0.25 $\mathrm{uL}$ of $10 \mathrm{uM}$ forward primer; $0.25 \mathrm{uL}$ of $10 \mathrm{uM}$ reverse primer; $4 \mathrm{uL}$ of a 1:10 dilution of cDNA template (corresponding to approximately $8 \mathrm{ng}$ RNA). The thermal cycle conditions were: $50{ }^{\circ} \mathrm{C}$ for $2 \mathrm{~min}, 95^{\circ} \mathrm{C}$ for $10 \mathrm{~min}$, 45 cycles at $95{ }^{\circ} \mathrm{C}$ for $15 \mathrm{~s}$, and $62^{\circ} \mathrm{C}$ for $1 \mathrm{~min}$, and a final dissociation step at $95{ }^{\circ} \mathrm{C}$ for $15 \mathrm{~s}, 65^{\circ} \mathrm{C}$ for $15 \mathrm{~s}$, and 95 ${ }^{\circ} \mathrm{C}$ for $15 \mathrm{~s}$. The qPCR cycle threshold $(\mathrm{Ct})$ was set in the middle of the exponential phase of the amplification. Also, appropriate positive and negative controls were included in each run. In each experiment, the individual sample was run in triplicate and the $\mathrm{Ct}$ of each well was recorded at the end of the reaction. The mean and standard deviation (SD) of the three Cts were calculated and the average value was accepted if the triplicate $\mathrm{Ct}$ values were within $\pm 1 \mathrm{Ct}$.

For each sample, HLA-DRB1 expression was presented as the ratio between HLA-DRB1 and the endogenous control ( $\beta$-ACTIN) using the $2-\Delta \Delta C t$ method [34]. The identity of polymerase chain reaction (PCR) products was verified by sequencing.

\section{Statistical analysis}

SPSS 17.0 was used for all statistic analyses. The methylation and RT-PCR results are presented as mean \pm SE. The t-test was used to compare the difference between paired and unpaired observations. Adjusted odds ratios (ORs) were calculated by fitting logistic regression models with adjustment. $P$-values $<0.05$ were considered statistically significant.

\section{ACKNOWLEDGMENTS}

The authors would like to thank Dr Fang Fang, Dr Liang Zhao, Dr Yan Wang, Dr Qiang Wang, Dr Liming Huang, Guohua Wu, Chunyan Cao and Xiaoli Fan for their assistance in collecting materials, and all study subjects for providing skin samples for assessment of DNA methylation and mRNA expression. This work was supported by these grants from Jiangsu natural science foundation (BK2008093 and BK2016438).

\section{CONFLICTS OF INTEREST}

The authors state no conflict of interest.

\section{REFERENCES}

1. Bowcock AM. The genetics of psoriasis and autoimmunity. Annu Rev Genomics Hum Genet 2005; 6:93-122.

2. Bozduman T, Ersoy Evans S, Karahan S, Hayran Y, Akbiyik F, Lay I. Genetic Risk Factors for Psoriasis in Turkish Population: -1540 C/A, -1512 Ins 18, and +405 C/G Polymorphisms within the Vascular Endothelial Growth Factor Gene. Ann Dermatol. 2016; 28:30-39.

3. Cassia FF, Carneiro SC, Marques MT, Pontes LF, Filgueira AL, Porto LC. Psoriasis vulgaris and human leukocyte antigens. J Eur Acad Dermatol Venereol. 2007; 21:303-310. Review.

4. Zhou F, Wang W, Shen C, Li H, Zuo X, Zheng X, Yue M, Zhang C, Yu L, Chen M, Zhu C, Yin X, Tang M, Li Y, Chen G, Wang Z, Liu S, Zhou Y, Zhang F, Zhang W, Li C, Yang S, Sun L, Zhang X. Epigenome-Wide Association Analysis Identified Nine Skin DNA Methylation Loci for Psoriasis. J Invest Dermatol. 2016; 136:779-787. 
5. Chen M, Chen ZQ, Cui PG, Yao X, Li YM, Li AS, Gong JQ, Cao YH. The methylation pattern of p16INK4a gene promoter in psoriatic epidermis and its clinical significance. Br J Dermatol. 2008; 158:987-993.

6. Marsh SG, Albert ED, Bodmer WF, Bontrop RE, Dupont B, Erlich HA, Geraghty DE, Hansen JA, Hurley CK, Mach B, Mayr WR, Parham P, Petersdorf EW, Sasazuki T, Schreuder GM, Strominger JL, Svejgaard A, Terasaki PI, Trowsdale J . Nomenclature for factors of the HLA System, Tissue Antigens. 2004; $65: 301-369$.

7. Mazokopakis EE, Kotsiris DA. Hashimoto's autoimmune thyroiditis and vitamin D deficiency. Current aspects. Hell J Nucl Med. 2014; 17:37-40.

8. Genetzakis M1, Gomatos IP, Georgiou AN, Giotakis J, Manolopoulos L, Papadimitriou K, Chra H, Leandros E, Tsigris C, Ferekidis EA. BCL-2, p53 and HLA-DRB1 antigen expression in surgically treated parotid cancer patients. Eur Arch Otorhinolaryngol. 2009; 266:417-424.

9. Rangel LB1, Agarwal R, Sherman-Baust CA, MelloCoelho Vd, Pizer ES, Ji H, Taub DD, Morin PJ. Anomalous expression of the HLA-DRB1 alpha and beta chains in ovarian and other cancers. Cancer Biol Ther. 2004; 3:10211027.

10. Kunihiro M,Tanaka S,Haruma K,Yoshihara M,Sumii K,Kajiyama G,Shimamoto F. Combined expression of HLA-DRB1 antigen and proliferating cell nuclear antigen correlate with colorectal cancer prognosis. Oncology. 1998; 55: 326-333.

11. De Bruin EC,van de Velde CJH,van Krieken JH,Marijnen CA,Medema JP. Epithelial human leukocyte antigen-DR expression predicts reduced recurrence rates and prolonged survival in rectal cancer patients. Clin Cancer Res. 2008; 14: 1073-1079.

12. Walsh MD1, Dent OF, Young JP, Wright CM, Barker MA, Leggett BA, Bokey L, Chapuis PH, Jass JR, Macdonald GA. HLA-DRB1 expression is associated with better prognosis in sporadic Australian clinicopathological Stage C colorectal cancers. Int J Cancer. 2009; 125:1231-1237.

13. Bettencourt A, Carvalho C, Leal B, Brás S, Lopes D, Martins da Silva A, Santos E, Torres T, Almeida I, Farinha F, Barbosa P, Marinho A, Selores M, Correia J, Vasconcelos C, Costa PP, da Silva BM. The Protective Role of HLA-DRB1B1* 13 in Autoimmune Diseases. J Immunol Res. 2015:948723.

14. Revenfeld AL, Steffensen R, Pugholm LH, Jørgensen MM, Stensballe A, Varming K. Presence of HLA-DR molecules and HLA-DRB1 mRNA in circulating CD4+ T cells. Scand J Immunol. 2016 Jul 15; doi: 10.1111/sji.12462.

15. Nagafuchi Y, Shoda H, Sumitomo S, Nakachi S, Kato R, Tsuchida Y, Tsuchiya H, Sakurai K, Hanata N, Tateishi S, Kanda H, Ishigaki K, Okada Y, Suzuki A, Kochi Y, Fujio K, Yamamoto K. Immunophenotyping of rheumatoid arthritis reveals a linkage between HLA-DRB1 genotype, CXCR4expression on memory CD4(+) T cells, and disease activity. Sci Rep. 2016; 7;6:29338.
16. Morhenn VB, Abel EA, Mahrle G. Expression of HLADRB1 antigen in skin from patients with psoriasis. J Invest Dermatol. 1982; 78:165-168.

17. Ho PY, Barton A, Worthington J, Plant D, Griffiths CE, Young HS, Bradburn P, Thomson W, Silman AJ, Bruce IN. Investigating the role of the HLA-CW*06 and HLA-DRB1B1 genes in susceptibility to psoriatic arthritis: comparison with psoriasis and undifferentiated inflammatory arthritis. Ann Rheum Dis. 2008; 67:677-682.

18. Shawkatová I, Javor J, Párnická Z, Kozub P, Zilínková M, Frey P, Ferenčík S, Buc M. HLA-C, DRB1 and DQB1 alleles involved in genetic predisposition to psoriasis vulgaris in the Slovak population. Folia Microbiologica. 2013; 58:319-324.

19. Cardoso CB, Uthida-Tanaka AM, Magalhães RF, Magna LA, Kraemer MH. Association between psoriasis vulgaris and MHC-DRB, -DQB genes as a contribution to disease diagnosis. Eur J Dermatol. $2005 ; 15: 159-163$.

20. Yang S, Ge HS, Zhang AP, Wei SC, Gao M, Wang HY, Chen JJ, Li M, Liang YH, He PP, Yang J, Zhang XJ. Haplotype associations of the MHC with psoriasis vulgaris in Chinese Hans. Clin Exp Dermatol. 2004; 29:399-405.

21. Shen Z, Wang G, Fan JY, Li W, Liu YF. HLA DRB1*04, *07-restricted epitopes on Keratin 17 for autoreactive T cells in psoriasis. J Dermatol Sci. 2005; 38:25-39.

22. Magalhães RF, Biral AC, Pancoto JA, Donadi EA, Mendes CT Jr, Magna LA, Kraemer MH.Human leukocyte antigen (HLA) and single nucleotide polymorphisms (SNPs) tumor necrosis factor (TNF)-alpha -238 and -308 as genetic markers of susceptibility to psoriasis and severity of the disease in a long-term follow-up Brazilian study. Int $\mathrm{J}$ Dermatol. 2010; 49:1133-1140.

23. Chen M, Wang Y, Yao X, Li C, Jiang M, Cui P, Wang B. Hypermethylation of HLA-C may be an epigenetic marker in psoriasis. J Dermatol Sci. 2016; 83:10-16.

24. Menendez L1, Walker LD, Matyunina LV, Totten KA, Benigno BB, McDonald JF. Epigenetic changes within the promoter region of the HLA-G gene in ovarian tumors. Mol Cancer. 2008; 7:43.

25. Moreau P1, Mouillot G, Rousseau P, Marcou C, Dausset J, Carosella ED. HLA-G gene repression is reversed by demethylation. Proc Natl Acad Sci U S A. 2003; 100:11911196.

26. Tang $\mathrm{Y}$, Liu $\mathrm{H}$, Li $\mathrm{H}$, Peng $\mathrm{T}, \mathrm{Gu} \mathrm{W}, \mathrm{Li} \mathrm{X}$. Hypermethylation of the HLA-G promoter is associated with preeclampsia. Mol Hum Reprod. 2015; 21:736-744.

27. Nie Y, Yang G, Song Y, Zhao X, So C, Liao J, Wang LD, Yang CS. DNA hypermethylation is a mechanism for loss of expression of the HLA class I genes in human esophageal squamous cell carcinomas. Carcinogenesis. 2001; 22:16151623.

28. Jian Ming Hu, Ling Li, Yun Zhao Chen, Chunxia Liu, Xiaobin Cui, Liang Yin, Lan Yang, Hong Zou, Lijuan Pang, Jin Zhao, Yan Qi, Yuwen Cao, Jinfang Jiang, 
Weihua Liang, Feng Li. HLA-DRB1B1 and HLADQB1 methylation changes promote the occurrence and progression of Kazakh ESCC. Epigenetics. 2014; 9: 13661373.

29. Lei Yu, Lori B. Chibnik, Gyan P. Srivastava, Nathalie Pochet, Jingyun Yang, Jishu Xu, James Kozubek, Nikolaus Obholzer, Sue E. Leurgans, Julie A. Schneider, Alexander Meissner, Philip L. De Jager, David A. Bennett. Association of Brain DNA Methylation in SORL1, ABCA7, HLADRB1B5, SLC24A4, and BIN1 with Pathological Diagnosis of Alzheimer Disease. JAMA Neurol. 2015; 72: 15-24.

30. Graves M, Benton M, Lea R, Boyle M, Tajouri L, Macartney-Coxson D, Scott R, Lechner-Scott J. Methylation differences at the HLA-DRB1B1 locus in CD4+ T-Cells are associated with multiple sclerosis. Mult Scler. 2013; 20:1033-1041.
31. Roberson ED, Liu Y, Ryan C, Joyce CE, Duan S, Cao L, Martin A, Liao W, Menter A, Bowcock AM. A subset of methylated cpg sites differentiate psoriatic from normal skin. J Invest Dermatol. 2012; : 583-592.

32. Liu B, Fu Y, Wang Z, Zhou S, Sun Y, Wu Y, Xu A. HLADRB1 may be antagonistically regulated by the coordinately evolved promoter and 3'-UTR under stabilizing selection. PLoS One. 2011; 6:e25794.

33. Shen Z, Chen L, Liu YF, Gao TW, Wang G, Fan XL, Fan JY, Fan PS, Li CY, Liu B, Dang YP, Li CX. Altered keratin 17 peptide ligands inhibit in vitro proliferation of keratinocytes and $\mathrm{T}$ cells isolated from patients with psoriasis. J Am Acad Dermatol. 2006; 54:992-1002.

34. Pfaffl MW. A new mathematical model for relative quantification in real-time RT-PCR. Nucleic Acids Res. 2001; 29:e45. 